May 2008

\title{
EQUILIBRIUM IN FISCAL COMPETITION GAMES FROM THE POINT OF VIEW OF THE DUAL
}

\author{
By \\ Jeff Petchey \\ School of Economics and Finance \\ Curtin University \\ \& \\ Perry Shapiro \\ University of California

\section{Curtin籍 \\ University of Technology} \\ ISSN: 1835-9450 \\ ISBN: 978-1-74067-475-1
}

08.01 


\title{
EQUILIBRIUM IN FISCAL COMPETITION GAMES FROM THE POINT OF VIEW OF THE DUAL
}

\author{
Jeffrey D Petchey $^{1}$ and Perry Shapiro ${ }^{2}$
}

\begin{abstract}
$\underline{\text { Abstract }}$
Papers that examine fiscal competition for mobile factors of production commonly employ simultaneous move games between two states and focus on the inefficiency of the equilibria. Most often, the existence of the equilibrium is left unexplored. By examining decision making by governments that make only constrained efficient choices, we derive sufficient conditions for the existence of equilibria when there are multiple policy instruments, multiple mobile factors and many different production processes. Convexity of the minimum cost function, "dual" to the factor preferences and production function primitives, is sufficient to ensure the existence of equilibrium. We also find that equilibrium may not exist because of the economies of scale inherent in provision of public goods which benefit mobile factors.
\end{abstract}

JEL Classifications: HO, RO.

Keywords: fiscal competition, existence, duality, cost functions, public goods.

\footnotetext{
${ }^{1}$ School of Economics, Curtin University, WA, Australia.

${ }^{2}$ Department of Economics, University of California, Santa Barbara, USA. The authors owe a debt of gratitude to Susana Peralta who read several versions of the paper. Her comments spared us the embarrassment of undiscovered errors and led us to appreciate subtleties we had not understood. We also wish to thank the anonymous referees for their insightful suggestions.
} 


\section{Introduction.}

An extensive literature has emerged exploring the properties of Nash equilibria in games of fiscal competition between states within federations, and between nation-states within regional unions. Surveys of this literature can be found in Wilson and Wildasin (2004), Wilson (1999), as well as Cremer, Fourgeaud, Leite Monteiro and Pestieau (1996). The key idea to emerge from the early papers is that equilibrium outcomes are inefficient because fiscal competition creates fiscal externalities which lead to inefficient provision of local public goods and a misallocation of mobile factors of production, in particular capital, between the competing states. These papers assume that governments are benevolent welfare maximizers; fiscal competition is, therefore, welfare reducing, requiring corrective policies or cooperation to achieve Pareto optimal outcomes (Wildasin (1989)).

Subsequent work has explored the potential for fiscal competition to be welfare enhancing. Much of this work dates from the Brennan and Buchanan (1980) Leviathan model where governments are revenue maximizers. In this world, fiscal competition provides a welfare improving constraint on the taxing powers of government. Overall, whether fiscal competition is welfare enhancing or reducing depends therefore on the degree to which governments pursue welfare maximizing versus revenue maximizing goals (Edwards and Keen (1996)).

Recently, researchers have examined the empirical importance of the costs and benefits of fiscal competition (Parry (2003)) and the welfare gains from regional tax coordination (Sorensen (2004)). Others have examined why there has not in practice been a 'race to the bottom' as some fiscal competition models predict (Mendoza and Tesar (2005)). This has been an especially important issue in the European Union where the potential need for tax coordination has been much debated.

The standard fiscal competition model employed has its foundation in the papers by Zodrow and Mieszkowski (1986) and Wildasin (1988) though the models developed since this early work vary in terms of hypotheses about how states engage in fiscal competition. For example, differing assumptions are made about the degree of firm competition, regional factor market integration, the extent to which mobile factors are attached to their home state, the types of mobile factors over which states compete, the 
vector of tax and policy instruments at the disposal of states and the structure of the games themselves (e.g. simultaneous, sequential).

The focus of analysis has been on characterizing the properties of Nash equilibrium outcomes with most papers assuming the existence of equilibrium (for example, Wildasin (1988), page 233). Few have directly confronted the difficult question of whether equilibrium exists. One exception is to be found in the paper by Wilson (1991) who analyzes linear state best reply curves. Wildasin (1991) also examines existence for a series of special cases with quasi-linear preferences and specific production technologies. Bucovetsky (1991) chooses a specific quadratic form for the production function which makes the marginal product of capital linear in taxes. This is sufficient to yield linear best reply curves and existence for the model constructed.

Laussel and Le Breton (1998) attempt a more ambitious proof of existence. They adopt most features of the standard model (e.g. as employed by Zodrow and Mieskowski (1986), Wildasin (1988)) though assume that mobile capital is owned by absentee landlords, or if owners live within a state, that they are disenfranchised. The effect is to exclude capital income from state objective functions. Laussel and Le Breton also suppose that state objective functions are linear in public and private consumption goods though this strips the fiscal competition game of its public good dimension. As will be seen in this paper, inclusion of public goods in the policy vector is important for the consideration of existence.

Bayindir-Upmann and Ziad (2005) revisit the existence problem and acknowledge that ' ...the existence issue is hard to deal with under the notion of a Nash equilibrium' . They go on to demonstrate existence and uniqueness of equilibrium in tax rates for the symmetric case using the concept of a second order locally consistent equilibrium - a weaker equilibrium notion than the Nash equilibrium.

The purpose of this paper is to tackle the issue of existence of Nash equilibrium in fiscal competition games and try to get further insight into this thorny issue. This is done by first developing a simple model based on what is perceived to be the standard model found in the literature. The simple model is of a regional bloc made up of $j=1,2$ states which share a common factor market with one mobile factor which can be thought of as

\footnotetext{
${ }^{3}$ See page 2 of Bayandir-Upmann and Ziad.
} 
capital or labor. State $j$ has two policy instruments, a per unit tax/subsidy and a local public good; thus, the model captures the tax and expenditure aspects of a state's budget ${ }^{4}$. State $j$ produces a numeraire good using fixed factors and the single mobile factor together with a quasi-concave production technology. The mobile factor receives a state specific payoff which, for given values of the state policy instruments, is a monotonically decreasing and concave function of the supply of the mobile factor in the state. By including the amount of the local public good as an argument of the mobile factor's payoff function, and the state production technologies, the public good is productivity enhancing. The mobile factor migrates between the states within the regional bloc to satisfy an equal payoff condition. The regional bloc's mobile factor market is also integrated with the world mobile factor market and its supply to the regional bloc is a non decreasing function of the (equal) payoff received within the bloc. Thus, the model allows for integration between the regional and world mobile factor markets in a way which caters for the two extreme cases of full integration, no integration, and all the cases in between (partial integration).

A state objective function is then developed which is separable into a benefit - the economic residual of the state - and cost component. It is argued that in a fiscal competition game with its neighbor, state $j$ will wish to choose its tax/subsidy and levels of public good provision policies to maximize the difference between benefit and cost, for given policies adopted by the neighboring state. This is shown to be equivalent to the dual problem of choosing tax/subsidy and public good policies to attract some desired level of mobile factor, at least cost. From this dual state optimization problem a state specific cost function is derived which expresses the least cost of achieving a given supply of the mobile factor in a state, conditional on the policies adopted by the neighboring state. Since the benefit component of the state objective is quasi concave in mobile factor supply existence is shown to depend only on the convexity of the state $j$ cost function in the supply of the mobile factor.

\footnotetext{
${ }^{4}$ The term regional bloc is used to encompass federations which have states or provinces, and regional unions of states, such as the European Union, which have independent nation states. It might also be more widely interpreted to include unitary states with decentralized systems of pubic finance (e.g. local jurisdictions) where there is the potential for fiscal competition.
} 
The insight that fiscal competition games can be thought of as dual games where the state objective is to choose policies to achieve a desired supply of mobile factors, conditional on neighbor state policies, and the result that existence depends only on the convexity of the underlying state $j$ cost function, are key contributions of the paper. However, there is more. Using two examples these results are extended to explore the implications (for existence) of the presence of public goods in the policy vector. One example assumes quasi linear preferences and the other Leontieff preferences. It is shown with both examples that convexity is not assured when there are economies of scale associated with the vector of public policies. One policy choice in particular, the level of output of local public goods, is prone to creating economies of scale and non convexity, except in the case where it is sufficiently crowded (or 'super crowded'). Hence, fiscal competition models which include insufficiently crowded public goods in the policy vector potentially have a problem with existence. The quasi linear example is also used to show that the only equilibrium which can arise in a fiscal competition model with pure local public goods and symmetric states (a case often examined), is one in which one state ceases to exist.

In the final sections of the paper the existence results obtained with the two state, two instrument and one mobile factor model are generalized to a model of a regional bloc with many states, multiple policy instruments and many mobile factors of production (e.g. different types of capital and labor). The existence results are then formally stated and proved in two theorems using the generalized model.

Before commencing, three points should be noted. First, the assumption that the state benefit is to maximize the economic residual of the state implies that income from the mobile factor accrues to non-resident mobile factor owners. This is the absentee capital owner assumption adopted by Laussel and Le Breton. The assumption is made to allow us to separate the state benefit and cost functions and, thus, to focus on the role of the cost function in explaining existence, and on the implications of economies of scale in public policies.

Second, use of the dual state optimization problem where states choose their policies to obtain a given quantity of mobile factor at least cost is a novel approach to modeling fiscal competition games. The advantage of using the dual is that it simplifies 
the sufficient conditions needed for existence; they can be stated in terms of straightforward convexity conditions on a cost function, conditional on the concavity of the benefit function. Application of the dual in this context implies that state behavior is 'constrained Pareto efficient' as defined in Wilson (1991); that is, conditional on the instruments at their disposal, the policies adopted by other states and feasibility, the government of each state chooses an outcome such that it cannot make a citizen that it cares about better off without making another worse off. It should also be noted that sufficient and not necessary conditions for existence are derived. Thus, equilibrium may exist even if the convexity condition on the cost function is not satisfied.

Third, two prominent papers in the literature, Zodrow and Mieszkowski (1986) and Wildasin (1988) have formed the foundation for the standard model adopted in many subsequent papers. The simple primal model adopted in this paper has many of the features of the standard model developed in those foundation papers. This implies that the problem of non existence also potentially arises in these two prominent papers, and hence may be an issue in later research which adopt a similar modeling structure. For example, in the Wildasin (1988) paper states have pure local public goods in their policy vector - as noted above the results here suggest that un-crowded public goods cause non convexity in the cost function, and potentially, non existence. The Wildasin paper also deals with symmetric outcomes as do many subsequent models; however, the quasi linear example demonstrates that this leads to an equilibrium in which one state fails to exist.

The outline of the paper is as follows: Section II sets up the two state one mobile factor and two instrument model of a regional bloc. In Section III the separable cost and benefit parts of the state objective function are set up and the properties of the cost function in particular are explored. Section IV explains the sufficient condition for existence as a convexity condition on the cost function, conditional on concavity of the benefit function. In Section $\mathrm{V}$ the problems that public goods pose for existence are explored using two examples, one with quasi-linear preferences and the other with Leontief preferences. Section VI provides more general results by extending the model to allow for multiple instruments, states and mobile factors. Section VII concludes. 


\section{Two State, One Mobile Factor and Two Instrument Model.}

Assume a simple fiscal competition model with one mobile factor and two states, labeled $j=1,2$. In order to economize on the presentation the subscript $j(=1,2)$ is used to identify the decision making state, and $-j$ to denote its neighbor. Each state has a distinct production technology and two policy instruments. The states are linked through a common factor market as part of a regional bloc. Later, in Section VI, it is shown that the results generalize to a world in which there are many states with multiple policy instruments, and mobile factors of production. The advantage of the simple model is that it allows us to focus on existence in terms of conditions on a state specific cost function and highlight the problem that public goods cause for existence.

\section{(a) Production Technology}

Each state has potentially different production technologies which yield output of a numeraire commodity. Whilst the numeraire commodities produced by the states may, or may not, be the same, their prices are assumed to be fixed. The quantity of the numeraire produced in state $j$, multiplied by the fixed price, is the output of the state $y_{j}$. State output is a strictly quasi concave function of the amount of a single mobile factor $n_{i}$ employed within the state. The mobile factor can be thought of as labor or capital. The total quantity of the mobile factor available to the regional bloc is $n=n_{1}+n_{2}$. As is shown later, $n$ can vary as the mobile factor moves in and out of the regional bloc depending on the within-bloc reward relative to its reward elsewhere, and is free to move without cost or restriction between the two states. Also, let $N$ be the world supply of the mobile factor where $n \leq N$.

The government of state $j$ has two policy instruments, a unit tax/subsidy $s_{j}$ where positive values imply a subsidy and negative values a tax, and a local public good, $q_{j}$. The policy vector of state $j$ is defined as $\sigma_{j}=\left(s_{j}, q_{j}\right) \in S_{j}$ where $S_{j}$ is the set of feasible strategies. The strategy set for the two states is $S=S_{1} \times S_{2}$ which is assumed to be a nonempty, convex and compact sub set of some Euclidian space, that is, $S \in \square^{M}$. 
The local public good is productivity enhancing and also enters each state's production function. ${ }^{5}$ Output in each state is strictly quasi-concave in the quantity of the public good supplied. The state-specific technologies are therefore specified by the production function

$$
y_{j}=f_{j}\left(n_{j}, q_{j}\right) \text {. }
$$

The marginal product of the mobile factor is always positive while the marginal product of the local public good is non-negative. The weaker inequality for the public good is chosen to allow for the possibility that the good may be one that only enhances the welfare of the mobile factor (see later) without increasing productivity. We also assume that the marginal productivity of one input is not diminished by the quantity of the other. These conditions are

$$
\frac{\partial f_{j}}{\partial n_{j}}>0, \quad \frac{\partial f_{j}}{\partial q_{j}} \geq 0, \quad \frac{\partial^{2} f_{j}}{\partial n_{j} \partial q_{j}} \geq 0 .
$$

The addition of one further assumption simplifies the later analysis in that it ensures that the excess of state output over the payment to the mobile factor (residual) is a concave function of $n_{j}$, the total mobile factor supply to state $j$. The assumption is that $^{6}$

$$
\frac{\partial^{3} f_{j}\left(n_{j}, q_{j}\right)}{\partial n_{j}^{3}} \geq 0 .
$$

Within each state and within the regional bloc the market for the mobile factor is perfectly competitive and is paid a return $w_{j}$ which is equal to the value of its marginal product,

$$
w_{j}=\frac{\partial f_{j}\left(n_{j}, q_{j}\right)}{\partial n_{j}}=w_{j}\left(n_{j}, q_{j}\right) .
$$

It follows from the assumptions stated above that the mobile factor return in each state is monotonically decreasing in the quantity employed (diminishing returns) and nondecreasing in the quantity of the local public good.

\footnotetext{
${ }^{5}$ For example, public infrastructure investment in roads enhances the efficiency of distribution.

${ }^{6}$ A similar condition is employed by Laussel and Le Breton.
} 


\section{(b) Mobile Factor 'Payoff'}

The mobile factor 'payoff' $P_{j}$ in state $j$ is a function of the policy vector of state $j$ and the quantity of the mobile factor present in the state,

$$
P_{j}=P_{j}\left(\sigma_{j}, n_{j}\right) .
$$

Since the public policy is measured as its positive contribution to mobile factor welfare (e.g., subsidies instead of taxes) $P_{j}\left(\sigma_{j}, n_{j}\right)$ is monotonically increasing in $\sigma_{j}$.

Consider the case where the mobile factor is labor and the payoff is utility - here the payoff function is $P_{j}=u_{j}\left(w_{j}\left(n_{j}, q_{j}\right)+s_{j}, q_{j}\right)$. We assume that the utility function is concave in income and the public good. Since $w_{j}(\cdot)$ is monotonically decreasing in $n_{j}$, utility is monotonically decreasing in $n_{j}$. Alternatively, if we consider the mobile factor to be capital the payoff is simply the net return, $P_{j}\left(\sigma_{j}, n_{j}\right)=w_{j}\left(n_{j}, q_{j}\right)+s_{j}$. This is monotonically decreasing in $n_{j}$ and quasi-concave in the public good and the tax/subsidy. Thus, for capital and labor the payoffs are strictly quasi-concave in the public policies, $\sigma_{j}$, and monotonically decreasing in the supply of the mobile factor, $n_{j}$ for $j=1,2$. Also, it is assumed that $P_{j}\left(\sigma_{j}, n_{j}\right)$ is positive and finite for all $n \in(0, n]$.

The monotonic and quasi-concavity features of the mobile factor payoff function follow from the 'primitives' of the production technology and preferences. As will be seen below, these features of the mobile factor payoff function are pivotal to formulating the fiscal competition game in terms of a dual and the sufficient condition for existence.

\section{(c) Mobile Factor Market Equilibrium Conditions}

Fiscal competition models commonly suppose that there is a given amount of a single mobile factor within the regional bloc which migrates without cost between states to equate some equal return condition; utility for labor and after tax marginal product for capital. A few papers allow integration between the regional bloc's mobile factor market and world factor markets (integration). Examples of papers which allow for fully open factor markets include Oates and Schwab (1988), Bocovetsky and Wilson (1991) and Keen and Marchand (1997). Papers that accommodate both extremes - fully closed and 
open mobile factor markets - and the intermediate cases of partially open markets, include Sorensen (2003), as well as Petchey and Shapiro (2002).

In this paper the mobile factor is allowed to migrate without cost or attachment to place between the two states, and also between the regional bloc and the rest of the world in such a way that captures the extremes of fully open and closed markets, and all cases in between (partial integration). This implies that the existence result holds for this quite general case of factor market integration, as well as the more restrictive case of closed markets usually found in the literature. To economize on the presentation in this and the following section the subscript $j(=1,2)$ is used to indicate the decision making state and $-j$ to indicate its regional partner. The only restriction placed on migration between the bloc and the world is that it responds rationally to the within-bloc mobile factor payoff.

Within the regional bloc the following mobile factor market payoff condition holds

$$
P_{j}\left(\sigma_{j}, n_{j}\right)=P_{-j}\left(\sigma_{-j}, n_{-j}\right) .
$$

The supply of the mobile factor to the regional bloc denoted as $n$ is a monotonically nondecreasing function of the within bloc (equal) payoff. It can, therefore, be expressed as a functional relation

$$
n=n_{j}+n_{-j}=n\left(P_{j}\left(\sigma_{j}, n_{j}\right)\right) .
$$

This functional form encompasses the case of a fully closed regional factor market in which $n$ is unresponsive to changes in the regional payoff, a regional factor market that is fully open to the world (the within-region mobile factor payoff is equal to the world payoff) and the partial integration cases in between. It is important to note that the regional mobile factor supply function is non-decreasing in both policies and monotonically increasing in $P_{j}(\cdot)$.

\section{(d) Concavity and Continuity Conditions}

The mobile factor equilibrium conditions (2.6) and (2.7), and the concavity and continuity properties of the mobile factor payoff function which arise from the underlying primitives of the production technology and preferences, are now used to demonstrate that the supply of the mobile factor to any one state within the regional bloc is a 
continuous and strictly quasi-concave function of its policy choices, conditional on the choices made by its neighbor. Quasi-concavity and continuity of a state's mobile factor supply in its strategy choice is a crucial part of our discussion of existence and the features of the cost function sufficient to ensure existence.

The mobile factor market equilibrium conditions (2.6) and (2.7) can be written as one implicit function ${ }^{7}$

$$
h\left(\sigma_{j}, \sigma_{-j}, n_{j}\right)=P_{j}\left(\sigma_{j}, n_{j}\right)-P_{-j}\left(\sigma_{-j}, n\left(P_{j}\left(\sigma_{j}, n_{j}\right)\right)-n_{j}\right)=0
$$

As shown in section (b) above $P_{j}\left(\sigma_{j}, n_{j}\right)$ is monotonically decreasing in $n_{j}$ for all $\sigma_{j}$. Therefore, the implicit function (2.8) is monotonically decreasing in $n_{j}$. Since $P_{j}\left(\sigma_{j}, n_{j}\right)$ is continuous in $n_{j}$ then $h(\cdot)$ is also continuous in mobile factor supply $n_{j}$. We now state and prove two propositions about the mobile factor market equilibrium condition (2.8) which are crucial to our analysis of existence and the cost function.

Proposition 1: For $\sigma_{j} \in S_{j}$ there is a unique $n_{j}$ that satisfies the mobile factor market equilibrium condition, $h\left(\sigma_{j}, \sigma_{-j}, n_{j}\right)=0$. This implies a functional relationship between $n_{j}$ and $\sigma_{j}$, conditional on $\sigma_{-j}$. In turn, this implies that we can define

$$
n_{j}\left(\sigma_{j}, \sigma_{-j}\right) .
$$

The proof of this is provided for the generalized version of the model presented later in the paper - see Section VI - where we have multiple mobile factors, instruments and states. The proof of the more general version of the proposition holds for the simple model we are dealing with here and therefore is not stated. Similarly, with the next proposition,

Proposition 2: $n_{j}\left(\sigma_{j}, \sigma_{-j}\right)$ is a strictly quasi-concave and continuous function of $\sigma_{j}$ and $\sigma_{-j}$.

\footnotetext{
${ }^{7}$ From (2.7) we can see that $n_{-j}=n\left(p_{j}\left(\sigma_{j}, n_{j}\right)\right)-n_{j}$. Using this in (2.6) yields the implicit function (2.8). For mobile factor market equilibrium we must have $h\left(\sigma_{j}, \sigma_{-j}, n_{j}\right)=0$.
} 
Again, the proof for this proposition is provided later in the paper - see proof for proposition 4 in Section VI - for the generalized model with multiple mobile factors, and hence is not stated here.

Having described the mobile factor equilibrium conditions, and shown the strict quasi-concavity and continuity conditions of state specific mobile factor supply in state strategies, conditional on neighboring state strategies, we next consider the objective of each state government. This, in turn, leads into our analysis of existence using the concavity and continuity conditions above.

\section{State Objectives}

State decision making is now examined in two parts. The first calculates, for each potential quantity of the mobile factor in state $j$, the least cost that needs to be incurred by the state to obtain that supply. The next part shows how the state will choose the mobile factor supply. This is the quantity that maximizes the difference between the benefit created for the state, or state profit, and the cost. Adopting a separable objective function in this way allows emphasize to be placed on the necessity for cost minimization given that states act efficiently. It also highlights the relationship between the shape of the cost function and existence. Finally, a sufficient condition for existence of a Nash equilibrium which relies on convexity of the cost function is discussed. For expositional convenience the analysis in this Section is pursued from the point of view of state $j=1$. Analogous results hold if the decision state is taken to be state 2 .

\section{(a) Cost Minimization}

Total expenditure by state 1 on the local public good and the tax/subsidy is given by the linear expression, $c_{1}=q_{1}+s_{1} n_{1}$. Finding the least cost policies which achieve a given supply of the mobile factor is the same as solving, for state 1, the following problem:

$$
\begin{aligned}
\underset{\left(\sigma_{1}\right)}{\operatorname{Min}} & c_{1}=q_{1}+s_{1} n_{1} \\
& \text { Sto }: n_{1}\left(\sigma_{1}, \sigma_{2}\right) \geq n_{1} .
\end{aligned}
$$

This policy choice problem is analogous to the theory of the firm where firms choose inputs to achieve a target level of output at least cost. The difference in interpretation is that here the state chooses policies rather than inputs to achieve a given 
level of mobile factor supply as opposed to output. Since $n_{1}=n_{1}\left(\sigma_{1}, \sigma_{2}\right)$ is quasi concave, provided that total expenditure (cost) is quasi-convex in the policies, there is at least one set of efficient (least cost) policies that solve (3.1). ${ }^{8}$ This is certainly true for the two instrument model where $c_{1}=q_{1}+s_{1} n_{1}$. One can, therefore, be assured of the existence of a cost function for state 1 which maps from policy choices, conditional on the policy choices of state 2 , to the least cost of achieving a desired mobile factor supply. This cost function is defined as:

$$
\begin{aligned}
C_{1}\left(n_{1} \mid \sigma_{2}\right) \equiv \underset{\left(\sigma_{1}\right)}{\operatorname{Min}} c_{1}=q_{1}+s_{1} n_{1} \\
\text { Sto }: n_{1}\left(\sigma_{1}, \sigma_{2}\right) \geq n_{1} .
\end{aligned}
$$

The nature of the cost function for the two instrument case can be clarified from the point of view of state 1 as follows. The price of each unit of the monetary subsidy $s_{1}$ is just $\$ 1$. Similarly, the cost or price of a unit of a local public good is a constant amount $^{9}$, again $\$ 1$. For a given $n_{1}$ expenditure by state 1 is a linear function of $q_{1}$ and $s_{1}$, namely, $c_{1}=q_{1}+s_{1} n_{1}$. As in the theory of the firm, define the iso-cost line as the combinations of $q_{1}$ and $s_{1}$ with the same expenditure or cost for the state. The iso-cost line can be expressed as $s_{1}=\left(c_{1}-q_{1}\right) / n_{1}$. The difference between this iso-cost line and the one encountered in the theory of the firm is that here its slope varies with $n_{1}$, which is equivalent to the price of an input changing with the level of production. The slope of the iso-cost line is simply

$$
\left.\frac{d s_{1}}{d n_{1}}\right|_{n_{1}}=-\frac{1}{n_{1}} .
$$

Since $n_{1}\left(\sigma_{1}, \sigma_{2}\right)$ is continuous and strictly quasi-concave in $\sigma_{1}$ for any $n_{1}$ there exists a convex set of policies that will yield a factor supply no less than $n_{1}$. This set is defined as $l\left(n_{1}\right)=\left\{q_{1}, s_{1} \mid n_{1}\left(q_{1}, s_{1}, \sigma_{2}\right) \geq n_{1}\right\}$. The boundary of $l\left(n_{1}\right)$ represents the minimum tax/subsidy necessary to yield $n_{1}$ for particular values of $q_{1}$, given the policies

\footnotetext{
${ }^{8}$ If there is more than one set of efficient strategies, each yields the same total cost.

${ }^{9}$ If $q_{1}$ is crowded and not produced at a constant marginal cost the per unit price is $m c_{1}\left(q_{1}\right) / A_{1}\left(n_{1}\right)$ where $A_{1}\left(n_{1}\right)$ represents crowding and $A_{1}^{\prime}\left(n_{1}\right)>0$.
} 
pursued by state 2 . In this paper the boundary is referred to as the iso-n curve to highlight the analogy with isoquants from production theory. The iso-n curves are convex to the origin in policy space. From the mobile factor equilibrium conditions the payoff to the mobile factor must be constant along an iso-n curve whose slope is given by (for state 1):

$$
\left.\frac{d s_{1}}{d q_{1}}\right|_{n_{1}}=-\frac{\partial n_{1} / \partial q_{1}}{\partial n_{1} / \partial s_{1}}
$$

To continue the analogy with the theory of the firm the left side of (3.4) is the marginal rate of technical substitution between the tax/subsidy and the public good for state 1 .

Since the iso-n curves are convex to the origin in two dimensional policy space and the iso-cost curve is linear, there is a unique tangency between any given iso-cost line and an iso-n curve. There is, therefore, a unique least cost policy combination, and, this implies the existence of a cost function as defined above. The iso-n and iso-cost curves, together with the least cost policy combinations associated with three possible desired quantities of the mobile factor, $n_{1}^{0}, n_{1}^{1}$ and $n_{1}^{2}$, are shown in Figure 1.

Consider iso-n curve $n_{1}^{0}$. With the iso-cost curve as drawn the least cost policy choice consistent with securing this supply of the mobile factor is $s_{1}^{0}, q_{1}^{0}$ (point A). This is a case where $s_{1}$ is negative (a tax). Now consider iso-n curve $n_{1}^{1}$. To obtain this larger supply of the mobile factor state 1 must spend more so the iso-cost line is to the right. The least cost policy choice which achieves this mobile factor supply is at the point where the iso-n curve consistent with $n_{1}^{1}$ is tangent to the new iso-cost line. Note, however, that as state 1 changes its spending the cost of the public good relative to the cost of the subsidy, $1 / n_{1}$, decreases. Hence, the slope of the iso-cost curve declines ( $n_{1}$ increases). This occurs because we are dealing with a public good. Therefore, the optimal policy mix needed to secure the higher mobile factor supply $n_{1}^{1}$ is something like $s_{1}^{1}, q_{1}^{1}$ on the Figure (point B). Similarly, the optimal policy mix associated with an even higher mobile factor supply, such as $n_{1}^{2}$, is $s_{1}^{2}, q_{1}^{2}$ (point C) where the slope of the iso-cost line has declined once more as $1 / n_{1}$ falls with higher $n_{1}$. 
Figure 1: Least Cost Mobile Factor

\section{Choice for State 1}

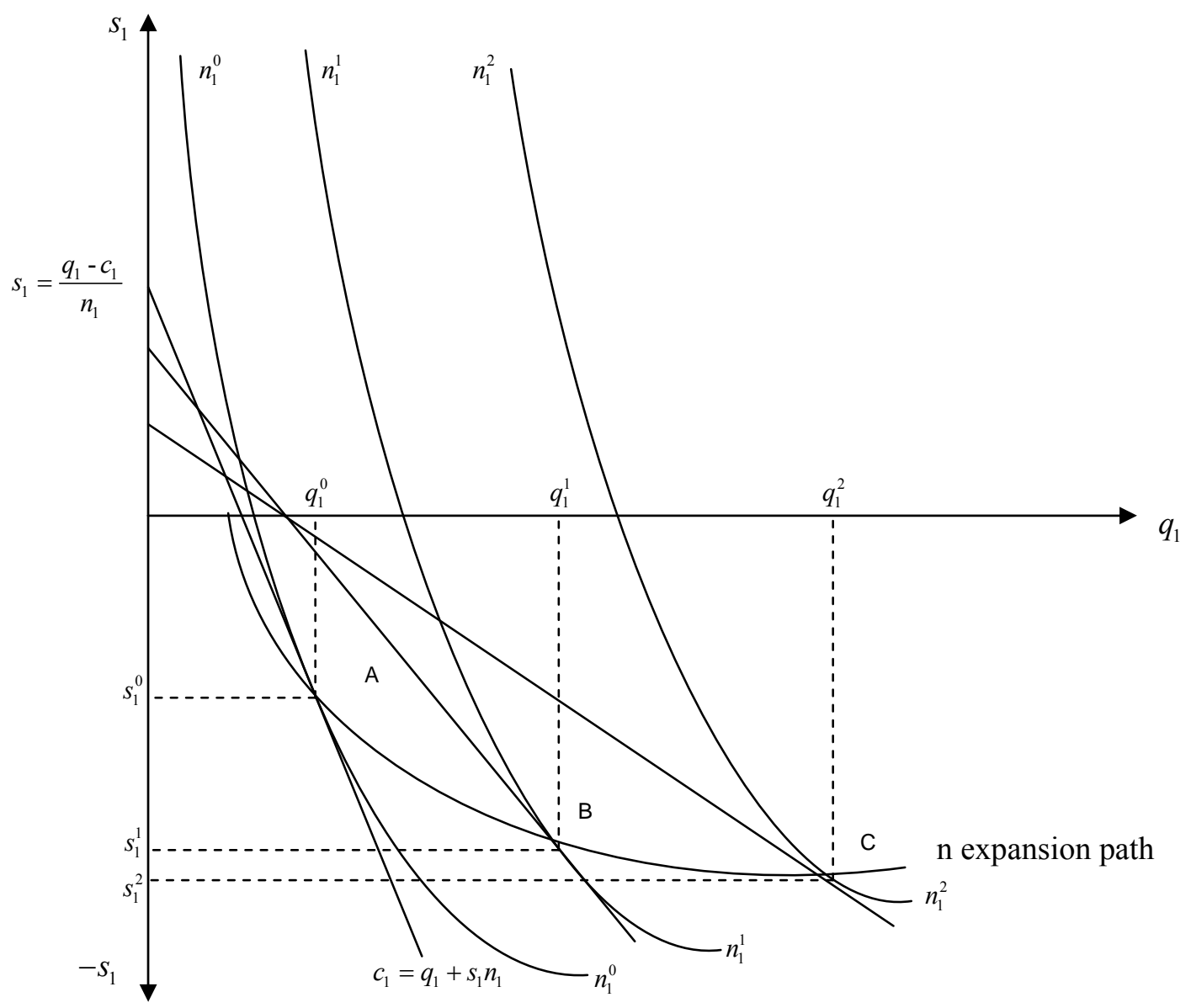

Thus, as state 1 spends more to attract higher levels of the mobile factor the isocost curve shifts to the right and becomes less steep, tracing an $n$-expansion path such as $\mathrm{ABC}$ in the Figure. The $n$-expansion path traces a locus of optimal (least cost) policy combinations associated with each quantity of mobile factor in state 1 . There is also a total (least) cost curve consistent with the $n$ expansion path which expresses least cost as a function of $n_{1}$; this is the cost function $C_{1}\left(n_{1} \mid \sigma_{2}\right)$ in (3.2). The total (least) cost curve can be of constant slope, implying constant returns with respect to $n_{1}$ (a doubling of expenditure on the tax/subsidy and the local public good yields double the mobile factor supply), convex, implying decreasing returns with regard to $n_{1}$ (double the expenditure yields less than double the supply of the mobile factor) or concave, implying increasing returns (double the expenditure yields more than double the mobile factor supply). 


\section{(b) State Benefits and Costs}

The discussion thus far has not been specific about what particular mobile factor supply a state might want. Rather, it has argued only that some given supply can be achieved at least cost using various policy mixes. The state objective must be broadened in order to explain how the state might calculate its desired mobile factor supply. This requires that one take into account any benefits that the state derives from the mobile factor in what can be thought of as a state benefit function. In this expanded objective the state will use the benefit function, together with the cost function derived above, to choose its optimal supply of the mobile factor. To achieve this broader objective a state must still choose the optimal factor supply at least cost.

A state might gain a number of benefits from the mobile factor. In particular, income generated by the mobile factor may accrue to permanent residents based on ownership. Including some fraction of mobile factor income in the state benefit function does not invalidate the subsequent analytic techniques, however, it does complicate considerably the analysis and this makes the task of highlighting the role of the cost function, and in particular, economies of scale in policies, difficult to relate clearly. Therefore, a straightforward benefit function is proposed, namely, the excess of state output over the mobile factor payment ${ }^{10}$. This is commonly thought of as the profit or residual accruing to the state, for example, to permanent, immobile, voting, residents. For state 1 the benefit function is defined as

$$
B_{1}\left(n_{1}, \sigma_{1} \mid \sigma_{2}\right)=f_{1}\left(n_{1}, \sigma_{1}\right)-w_{1}\left(n_{1}, \sigma_{1}\right) n_{1} .
$$

Condition (2.3) implies that the benefit function is strictly quasi-concave in the mobile factor supply. From the earlier discussion of (2.9) it is clear that $n_{1}\left(\sigma_{1}, \sigma_{2}\right)$ is strictly quasi-concave in $\sigma_{1}$ and $\sigma_{2}$. Therefore, the state 1 benefit function $B_{1}\left(n_{1}, \sigma_{1} \mid \sigma_{2}\right)$ is strictly quasi-concave in $\sigma_{1}$.

The state chooses its policies to maximize the difference between the benefit of a given mobile factor supply, as captured by (3.5), and the least cost of achieving that supply, as represented by the cost function. That is, state 1 chooses policies to maximize

\footnotetext{
${ }^{10}$ Thus, in common with Laussel and Le Breton, absentee ownership of mobile factors is implicitly assumed.
} 


$$
V_{1}\left(n_{1}, \sigma_{1} \mid \sigma_{2}\right)=B_{1}\left(n_{1}, \sigma_{1} \mid \sigma_{2}\right)-C_{1}\left(n_{1}, \sigma_{1} \mid \sigma_{2}\right) .
$$

The model of a regional union of states now has sufficient structure to examine existence of equilibrium.

\section{Existence}

The states are assumed to be players within a simultaneous move fiscal competition game where strategies are pure and continuous. It is a game because the strategies chosen by one state affect the allocation of the mobile factor across states as well as the total supply to the regional bloc, and hence the value of the objective function of the neighboring state. Thus, there is interdependence between states, induced by sharing a common factor market and by the integration of the bloc into the world factor market. Conjectures are assumed to be Nash - each state chooses its policies conditional on the choice of its neighbor. For expositional convenience the analysis is again undertaken from the perspective of state $j(=1,2)$ with $-j$ referring to the neighboring state (this is maintained for the rest of the paper). The approach is first to define a Nash equilibrium to the fiscal competition game and then explain what is sufficient for existence. This is followed by a diagrammatic exposition of the sufficient condition.

\section{(a) A Sufficient Condition}

A Nash equilibrium for state $j$ can be defined as follows:

Nash Equilibrium: State $j$ chooses $\sigma_{j}$ to maximize (3.6) conditional on $\sigma_{-j}$. The solution (best response) $\hat{\sigma}_{j}$ can be represented as a correspondence $\hat{\sigma}_{j}=\hat{\sigma}_{j}\left(\sigma_{-j}\right)$ between the strategies of state $-j$ and the best response of state $j$. This best response correspondence is a mapping from $S$ into itself. A Nash equilibrium is a fixed point to that mapping $\sigma^{*}=\left(\sigma_{1}^{*}, \sigma_{2}^{*}\right)$, such that $\sigma_{j}^{*}=\hat{\sigma}_{j}\left(\sigma_{-j}^{*}\right)$.

Commonly existence of a Nash equilibrium $\sigma_{j}^{*}=\sigma_{j}^{*}\left(\sigma_{-j}^{*}\right)$ is assumed, necessary conditions are derived from the state objective function that take account of factor 
mobility and feasibility, and the efficiency properties of the assumed equilibrium are examined.

However, from (3.6) it is straightforward to see what is sufficient for existence: if the cost function of state $\mathrm{j}$ is convex in its mobile factor supply then the objective function $V_{j}\left(n_{j}, \sigma_{j} \mid \sigma_{-j}\right)$ is strictly quasi-concave in $\sigma_{j}$. Since the objective function is continuous in state policies and the strategy set $S$ is defined on a non-empty, convex and compact sub-set of some Euclidean space, we know that a Nash equilibrium exists. This is an application of the theorem on existence of equilibrium in simultaneous move games with pure strategies (Mas-Colell, Whinston and Green (1995)) ${ }^{11}$. Note also that convexity of the cost function is a sufficient rather than necessary condition for existence.

Thus, if the benefit function is concave in the mobile factor supply a sufficient condition for existence hinges solely on the convexity of the cost function. It should be pointed out that if one allowed for residential mobile factor ownership this result may become more complex (as noted earlier, residential ownership is ruled out). Permanent resident mobile factor ownership means that a share of the marginal product generated by the mobile factor accrues to a class of permanent residents, with the exact share depending, for example, on a parameter which reflects the level of ownership. This raises the possibility that the state benefit function is not concave in mobile factor supply, as is the case where the benefit is simply the residual of the state. With residential ownership cost function convexity alone may therefore not be sufficient as the shape of the benefit function will also come into play in determining existence.

This is the paper's key contribution to the issue of existence in fiscal competition games. The idea is now expressed using a diagrammatic approach.

\section{(b) Diagrammatic Exposition}

The diagrammatic exposition commences with Figure 2 where a convex cost function, a concave benefit function and the resulting objective function for state $j$ are plotted, conditional on some given $\sigma_{-j}$. The objective function $V_{j}\left(n_{j}, \sigma_{j} \mid \sigma_{-j}\right)$ has a single maximum for the case illustrated. For some given policy vector chosen by state $-j$, point

\footnotetext{
${ }^{11}$ See page 253 of Mas-Colell, Whinston and Green (1995).
} 
A is a 'best response' with the desired mobile factor supply of $n_{j}^{*}$. The Figure highlights the necessity of cost minimization if the state is to maximize its objective $V_{j}\left(n_{j}, \sigma_{j} \mid \sigma_{-j}\right)$ - if the state does not choose cost minimizing policies then it cannot maximize this objective.

Figure 2: The Desired Mobile Factor Supply for State j

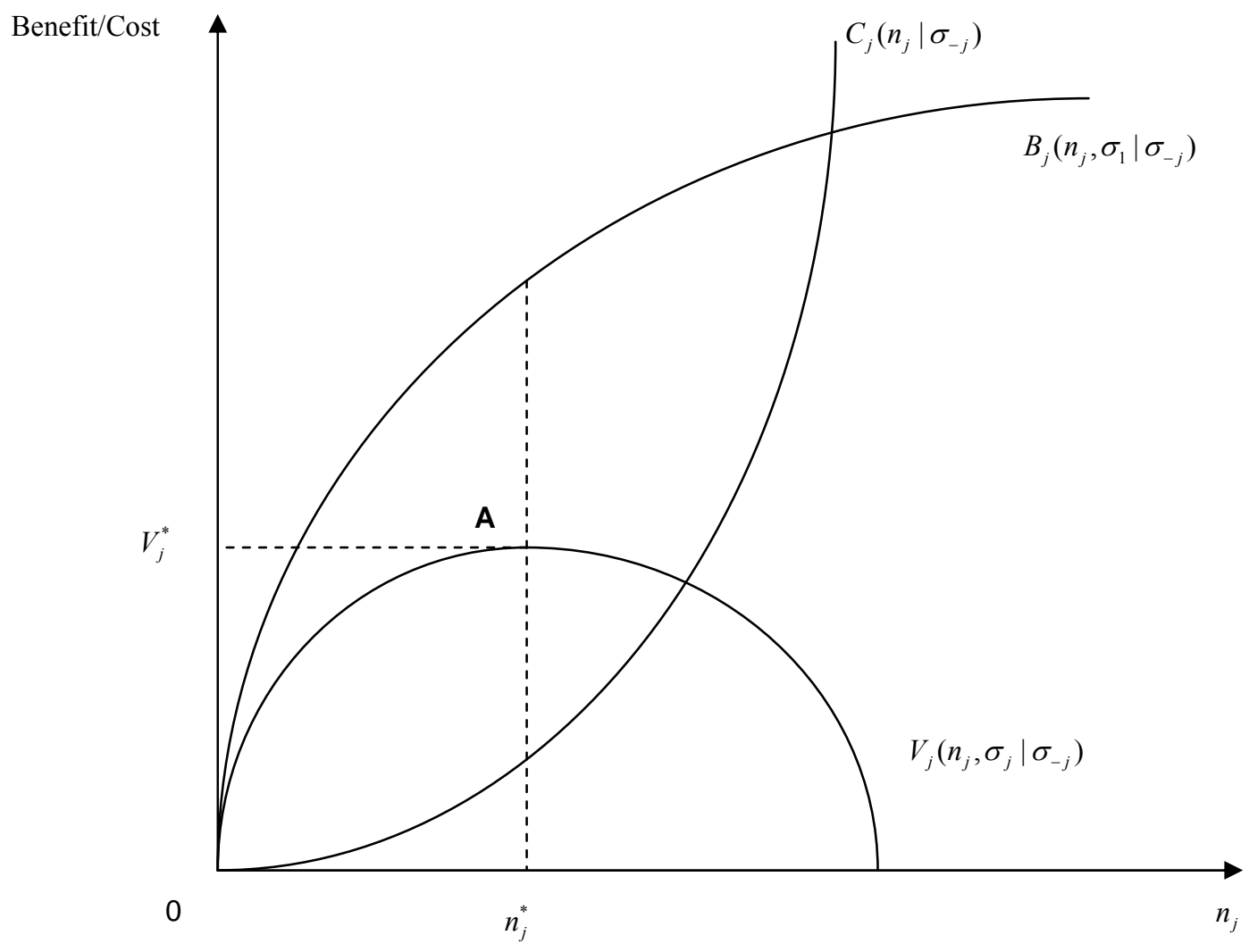

Existence can be further explained by taking the (least) cost curve and the optimal mobile factor supply associated with each cost and benefit curve, and deriving (graphically) the best reply curve for state $j$. This is done in Figure 3 below where, in Panel I, three (least) cost curves for state $\mathrm{j}$ are plotted, each one for a different value of the policies of its neighbor, $\sigma_{-j}$. (The benefit curve is not depicted since it does not shift in response to changes state $-j$ policies). The first (least) cost curve in Panel I, $C\left(n_{j} \mid \sigma_{-j}^{1}\right)$, assumes that the neighbor policies are $\sigma_{-j}^{1}$ and the associated optimal 
mobile factor demand by state $j$ is $n_{j}^{1^{*}} . n_{j}^{2^{*}}$ and $n_{j}^{3^{*}}$ are the optimal choices if $-j$ chooses ever larger values of $\sigma_{-j}$.

Figure 3: (Least) Cost and Best Response Functions for State j

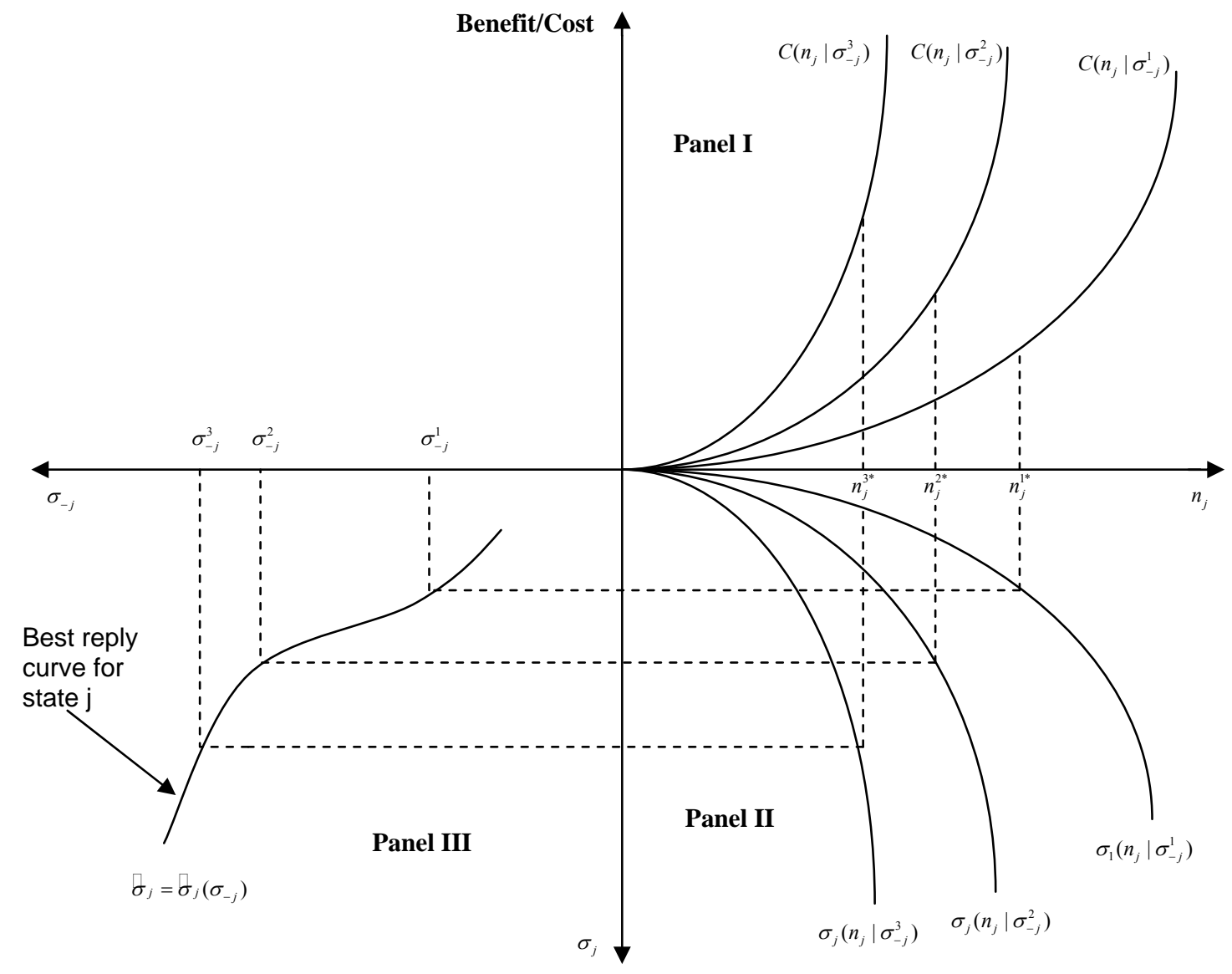

In Panel II the function $n_{j}\left(\sigma_{j}, \sigma_{-j}\right)$, which from proposition 2 is strictly quasiconcave and continuous in both arguments, is inverted. This allows the state $j$ policy vector to be expressed as a strictly quasi-concave and continuous function of its mobile factor supply, conditional on its neighbor's policy choice, $\sigma_{-j}$. Again, three curves are illustrated for different values of $\sigma_{-j}$, each one corresponding to a (least) cost curve in Panel I. From this it is possible to plot the best reply curve $\hat{\sigma}_{j}=\hat{\sigma}_{j}\left(\sigma_{-j}\right)$ for state $j$ in Panel III. This yields the state's best response, $\hat{\sigma}_{j}$ to any given policy chosen by its neighbor. 
A similar analysis can be undertaken for the neighboring state yielding an analogous bounded and continuous best reply curve, $\hat{\sigma}_{-j}=\hat{\sigma}_{-j}\left(\sigma_{j}\right)$. The best response functions of states $j$ and $-j$ (where $j=1,2)$ are illustrated on Figure 4.

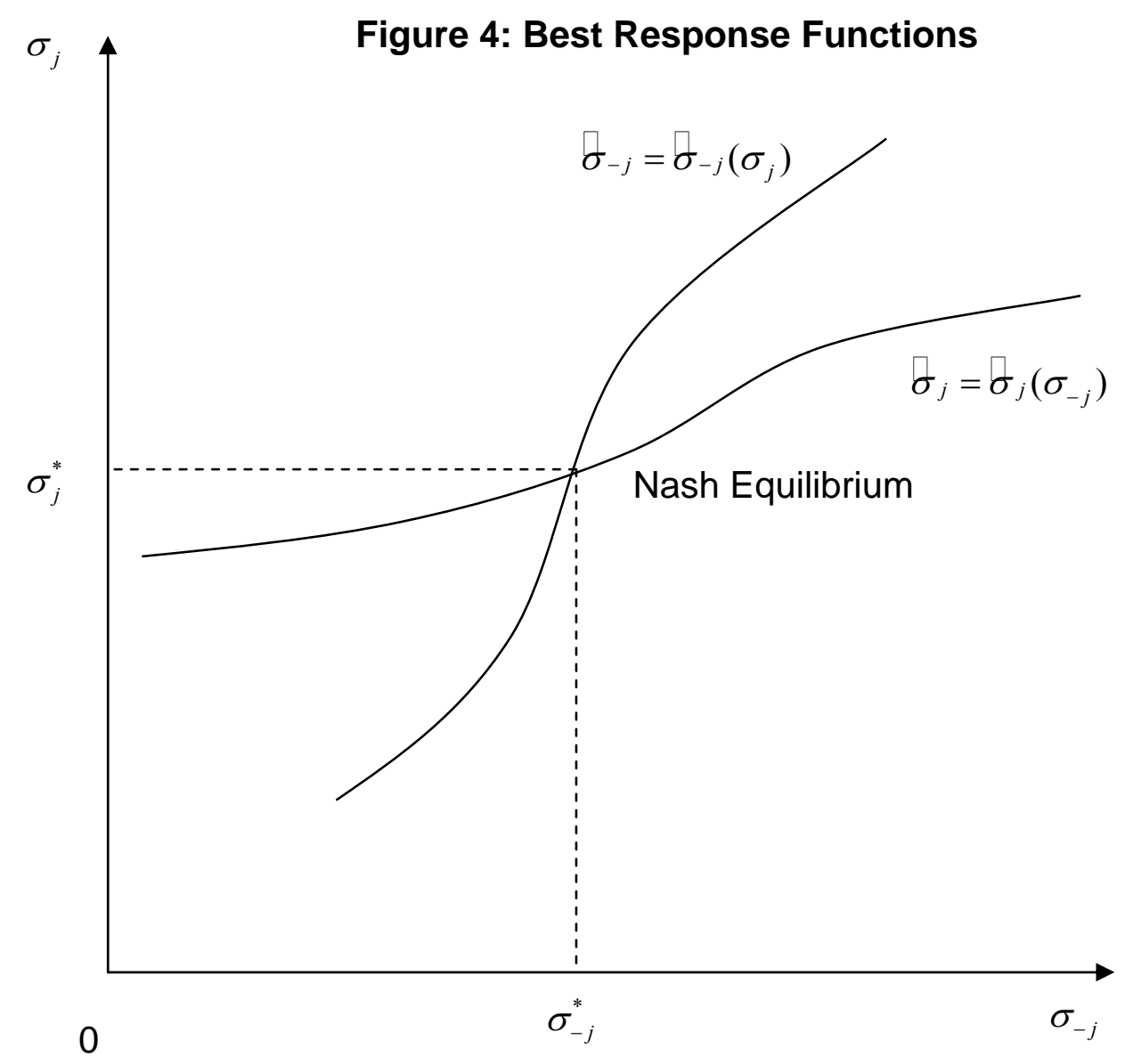

If the cost function is convex then there will be at least one intersection yielding an equilibrium policy pair such as $\sigma_{1}^{*}, \sigma_{2}^{*}$ and probably many, that is, multiple equilibria ${ }^{12}$.

\section{Public Goods and Existence}

The previous discussion emphasized that the presence of the public good in the state policy vector can lead to increasing returns in the policies and non-convexity of the cost

\footnotetext{
12 An anonymous referee raised the point that out of equilibrium behavior is an interesting and important issue in fiscal competition games. Our analysis of fiscal competition is constructed as a simultaneous move game and we derive sufficient conditions to ensure the existence of a Nash equilibrium to that game. Therefore, though interesting, out of equilibrium behavior is outside the scope of our work.
} 
function (Figure 2). This depends on the degree of 'publicness' associated with the public good. The implication is that public goods can create potential problems for existence of equilibrium in fiscal competition games. If the degree of increasing returns is sufficiently large equilibrium may not exist. This idea is now explored using two examples, one with quasi linear preferences and the other with Leontieff preferences.

\section{(a) Example 1: Quasi Linear Preferences}

The two states are again indexed by $j=1,2$ and the production technology of each is $y_{j}=\sqrt{n_{j}}$. The per unit return to the mobile factor is $1 /\left(2 \sqrt{n_{j}}\right)$. With this technology the benefit that accrues to the state is once more assumed to be the residual

$$
B_{j}=\sqrt{n_{j}}-0.5 \sqrt{n_{j}}=0.5 \sqrt{n_{j}} .
$$

At this point we introduce the notion of 'effective' public expenditures to allow for the possibility of crowding of the public good. This example will illustrate that the convexity of the cost function, and hence existence, depends on the degree of crowdedness. The effective public expenditure is $q_{j}^{*}=q_{j} / n_{j}^{2 \alpha}$ where the parameter $\alpha$ indicates the degree to which the public expenditure is crowded ${ }^{13}$. Thus, $\alpha=0$ indicates zero crowding, $\alpha=0.5$ indicates that crowding is proportional to the size of the mobile factor supply and $\alpha>0.5$ indicates that crowding (the diminution in effective usefulness) occurs faster than proportional to the factor supply.

The payoff to the mobile factor is a quasi-linear function of the monetary reward (the sum of the factor return, $w_{j}$, plus the monetary tax/subsidy, $s_{j}$ ) and the effective level of public expenditure, ${ }^{14}$

$$
P_{j}=w_{j}+s_{j}+\sqrt{q_{j}^{*}} .
$$

The state $j$ least cost function ${ }^{15}$ is

$$
C_{j}\left(n_{j} \mid \sigma_{-j}\right)=n_{j} P_{-j}-0.5 \sqrt{n_{j}}-0.25 n_{j}^{2(1-\alpha)} .
$$

\footnotetext{
${ }^{13}$ Sometimes this is labeled the publicness of the public good.

${ }^{14}$ The mobile factor payoff function is quasi-concave, not strictly quasi-concave since its Hessian is not negative semi-definite.

${ }^{15}$ Consult Annex A for derivation of the cost function.
} 
As discussed earlier there are two polar cases with regard to mobile factor market integration. The first has the mobile factor perfectly mobile between the regional bloc and the rest of the world. In these models the states are considered small relative to the world and the equilibrium factor payoff is fixed (for the states) at the world level. Hence, $P_{j}=P_{-j}=\bar{P}$ where $\bar{P}$ is the world determined value. For example, the models used in Oates and Schwab (1988), Keen and Marchand (1997) and Bucovetsky and Wilson (1991)) have this feature. The second case is one in which the states are isolated from the rest of the world and there is a fixed factor supply, $n<N$ (where $N$ is the given world supply), allocated to the regional bloc. As noted the game played between the states is one in which there is competition for the mobile factor and in equilibrium $P_{j}=P_{-j}$.

For the first case with a fixed value of $P$ (full integration) unless $\alpha$ is greater than 1 , that is, unless the public good is 'super-crowded', there is some value of $n_{j}$, say $n_{j}^{\prime}$, beyond which least cost is a declining function of the mobile factor supply. As long as the marginal benefit of the factor to the states remains positive, as it does with the technology in this example, the net benefit of more mobile factor continues to be positive and the potential surplus to any state is unbounded. In this case there is no equilibrium.

For the second case with the factor markets of the two states closed to the rest of the world, each state, when making its policy choices must account for the change those choices will induce in the equilibrium payoff $P_{j}$. An increase in one state's mobile factor supply must induce an equal decrease in the other state's supply, and, consequently, increase the mobile factor payoff in that state. Since the factor equilibrium condition requires interstate equality of the payoffs, a state must account for the change in this payoff when it considers its own option.

To make this idea concrete once again let $n$ be the total supply of the mobile factor available to the regional bloc. The second derivative of the cost function (5.3) is ${ }^{16}$

$$
\frac{d^{2} C_{j}}{d n_{j}^{2}}=n_{j} \frac{d^{2} P_{-j}}{d n_{j}^{2}}+2 \frac{d P_{-j}}{d n_{j}}+0.125 n_{j}^{-3 / 2}-0.5(1-\alpha)(1-2 \alpha) n_{j}^{-2 \alpha} .
$$

\footnotetext{
${ }^{16}$ See Annex A for derivation of the second derivative of the cost function and the derivatives of the mobile factor payoff function for state $-j$.
} 
It can be shown that the first and second derivatives of $P_{-j}$ are positive, irrespective of the value of $\alpha$. By inserting the expressions for the first and second derivatives from Annex A, expression (5.4) is

$$
\begin{aligned}
\frac{d^{2} C_{j}}{d n_{j}^{2}}= & \frac{3}{8} n_{j}\left(n-n_{j}\right)^{-5 / 2}+\alpha(1-\alpha) n_{j}\left(n-n_{j}\right)^{-(2+\alpha)} \sqrt{q_{-j}}+0.5\left(n-n_{j}\right)^{-3 / 2} \\
& +2 \alpha\left(n-n_{j}\right)^{-(1+\alpha)} \sqrt{q_{-j}}+0.125 n_{j}^{-3 / 2}-0.5(1-\alpha)(1-2 \alpha) n_{j}^{-2 \alpha}
\end{aligned}
$$

Global convexity of the cost function and the existence of equilibrium is assured if $\alpha$ is at least equal to 0.5 , that is, if the public good is proportionally, or 'super crowded'.

However, if $\alpha<0.5$, the cost function is not globally convex. This is so because for very small values of $n_{j}$ (for example, $n_{j} \rightarrow 0$ ) the final term of (5.5) (negative for $\alpha<0.5$ ) dominates all the preceding positive terms. Unless the public good is super crowded existence is, therefore, not assured.

Indeed, many fiscal competition models incorporate the special case of pure local public goods, where $\alpha=0$. This case can be explored further using the example. In this case, the second derivative of the cost function becomes

$$
\frac{d^{2} C}{d n_{j}^{2}}=\frac{3}{8} n_{j}\left(n-n_{j}\right)^{-5 / 2}+0.5\left(n-n_{j}\right)^{-3 / 2}+0.125 n_{j}^{-3 / 2}-0.5
$$

Because both states are the same in this example the only equilibrium, if it exists, is the symmetric one in which each state has half the total supply of the mobile factor. For the symmetric case $n_{j}=0.5 n$ and the second derivative when $\alpha=0$ is simply

$$
\frac{d^{2} C}{d n_{j}^{2}}=(0.5 n)^{-3 / 2}-0.5 \text {. }
$$

This is negative for any value of $n$ greater than 3.1748.

The second derivative of the benefit function at the symmetric allocation is ${ }^{17}$

$$
\frac{d^{2} B}{d n_{j}^{2}}=-0.125(0.5 n)^{-3 / 2}
$$

and the second derivative of the net benefit function $V_{j}=B_{j}-C_{j}$ is

\footnotetext{
${ }^{17}$ See Annex A.
} 


$$
\frac{d^{2} V_{j}}{d n_{j}^{2}}=-\frac{9}{8}(0.5 n)^{-3 / 2}+0.5 .
$$

The net benefit function is, therefore, convex for all values of $n$ greater than 3.43414 . Thus, a model with pure local public goods and symmetric states will only yield an equilibrium in which one state ceases to exist.

To summarize, this example demonstrates that there may be no equilibrium if public goods are not sufficiently crowded. Without crowding there is no constraint on the attractiveness of the public good relative to other policy instruments, as mobile factor supply expands, thus creating the possibility that the cost function loses the convexity required by the sufficient condition for existence of equilibrium.

\section{(b) Leontief Preferences}

The second example with Leontief preferences gives a little more insight into the problem that public goods pose for existence. Consider the same regional bloc but with the mobile factor payoff $P_{j}$ represented by a Leontief function, $P_{j}=\min \left\{\left(w\left(n_{j}\right)+s_{j}, q_{j}\right\}\right.$, with the mobile factor equilibrium condition, $P_{1}=P_{2}$. The equilibrium condition must encompass the restriction that mobile factor income $w(n)+s$ (since we only consider the symmetric case here the $j$ subscript is also dropped) and the public good are in equal proportions for both states. Now think of the consequence of one unit of the mobile factor moving from state 2 to state 1 . Because its factor supply has fallen, the state 2 wage increases. The Nash conjecture is that state 1 believes that the policies of state 2 remain unchanged. If that is the case, the marginal product of the mobile factor in state 2 is unchanged by the increased income (public good expenditures must rise proportionally). State 1, in order to attract the additional factor supply, must pay a subsidy (reduce its tax) by the exact amount of the increased supply induced wage decline. When the subsidy is changed by that amount, without changing the public good expenditure, the mobile factor payoff is the same in both states.

Since state costs are $c=n s+q$, state 1's marginal cost (the additional cost of attracting an additional unit of the mobile factor) is 


$$
\frac{d C}{d n}=s+n \frac{d s}{d n}=s-n \frac{d w}{d n} .
$$

For existence the cost function must be convex in $n$. Therefore, the second derivative

$$
\frac{d^{2} C}{d n^{2}}=2 \frac{d s}{d n}+n \frac{d^{2} s}{d n^{2}}=-2 \frac{d w}{d n}-n \frac{d^{2} w}{d n^{2}}
$$

is important. If the cost function is to be convex the second derivative must be positive. This will be the case if $\left|2 w^{\prime}(n)\right|>n w^{\prime \prime}(n)^{18}$.

The problem that the public good poses for existence is clear with this quasilinear form. Every dollar of per unit subsidy costs a state $n$ dollars in total costs. A dollar spent on public goods has undiminished benefits regardless of the size of the mobile factor supply. Additions to the mobile factor supply reduce its return, but since with the quasi-linear form the marginal rate of substitution between the public good and income is independent of the level of income, the value (to the mobile factor) of the public good is undiminished when its income falls. For this reason, states find it advantageous to substitute public expenditures on the public good for tax/subsidies as the mobile factor supply increases.

\section{(c) Summary}

The examples emphasize that the presence of the pure local public good as a policy instrument that provides a benefit to the mobile factor implies that a convex (least) cost curve is not assured. The inclusion of a public good in the policy vector, rather than exclusively focusing on taxes and tax competition, has implications for the existence of equilibrium; namely, it can violate the sufficient condition that the cost function should be convex in the mobile factor supply.

There needs to be something associated with the public good that offsets this possibility. On the cost side, one might allow for crowding, as shown in the first example, or increasing marginal cost of the public good - we have assumed that it can be produced at a constant cost of one, however, rising marginal cost due to decreasing

18 This condition is met naturally for the production function $y=n^{\alpha}$ and $\alpha<1$ : for this function $w(n)=\alpha n^{\alpha-1}$ with $w^{\prime}(n)=\alpha(\alpha-1) n^{\alpha-2}$ and $w^{\prime \prime}(n)=\alpha(\alpha-1)(\alpha-2) n^{\alpha-2}$. Thus, $n w^{\prime \prime}(n)=\alpha(\alpha-1)(\alpha-2) n^{\alpha-2}$. Since $(\alpha-1)(\alpha-2)<2$ the condition is met. 
returns in the production of the public good could be incorporated to make the public good less attractive with higher levels of mobile factor supply. Alternatively, there may be rigidities in substitutability between the public good and income within the mobile factor benefit function, as highlighted by the Leontief example, which make it less attractive for a state to use relatively more of the public good to secure higher levels of mobile factor supply.

\section{Generalization: Multiple Mobile Factors, States and Instruments}

The generalization includes an arbitrary number of states, indexed by $j$ where $j=1 \ldots J$, within a regional bloc. The following discussion sets out the production technology used within each state, the policy instruments adopted, the nature of factor mobility, and in particular how mobile factors of production move between states, and how they migrate between the common border of the regional bloc and the rest of the world.

In every state there are $k_{j}=1, \ldots ., K_{j}$ firms each producing a good with a given world price. Thus, the state's firms are small with respect to the rest of the world. Every product is produced using a strictly quasi-concave, differentiable, production function with $i=1, \ldots . ., I$ distinct mobile inputs. The amount of mobile input $i$ available world wide is a fixed amount, $N_{i}$. The quantity of mobile factor $i$ used by firm $k_{j}$ in state $j$ is $n_{i k_{j}} \leq N_{i}$. Furthermore, $n_{i j} \equiv \sum_{k_{j}} n_{i k_{j}}$ is the amount of factor $i$ used in state $j$ and $n_{i} \equiv \sum_{j} n_{i j}$ is the quantity of mobile factor $i$ used within the regional bloc. Naturally $n_{i} \leq N_{i}$ (i.e. the regional bloc may, or may not, use the world supply of the factor).

For every state $j$ there are multiple policy instruments indexed as $m_{j}=1, \cdots, M_{j}$. The policies are continuous in that they can take on all values in a closed continuous interval (e.g., tax rates between zero and one). All feasible policies constitute a bounded convex set $S_{j}$. The policy choices, strategies, of a state are designated as vectors $\sigma_{j}=\left(\sigma_{1 j}, \sigma_{2 j}, \cdots, \sigma_{m j}, \cdots, \sigma_{M j}\right), \sigma_{j} \in S_{j}$ The strategy set of all states is $S=S_{1} \times S_{2} \times \cdots \times S_{J}$. The vector of feasible policy choices for all states is $\sigma \equiv\left(\sigma_{1}, \sigma_{2}, \cdots, \sigma_{J}\right), \sigma \in \mathrm{S}$ 
The feasible strategy sets, $S_{j}$ 's, are naturally bounded by the finiteness of the resources available. For instance monetary subsidies paid to mobile factors, cannot exceed total production of a state. Thus, production technology, and the supply of inputs, limits state choices. Taxes are limited to the potential value of the tax base. Ad valorem tax rates, for instance, cannot exceed one. Since the game has continuous strategies any convex combination of two feasible policy vectors is a feasible policy choice.

Production of any good requires the use of at least one factor but can require the use of all or any number in between. Production technologies can be state specific, either because states adopt different production functions or have different fixed factor endowments. Productivity in a state may also depend on state policies. Public infrastructure investment, for instance, can have profound effects on the productivity, and thus the profitability, of state industry. We account for this as in the simple model presented earlier by assuming that the mobile factor payoff in state $j$ is a function of the state's public policies. In this way state policies affect mobile factor supply which in turn influences productivity.

Each firm in a state has its own production technology represented by a quasiconcave differentiable production function, $F_{k_{j}}$ of factor inputs and state policies. ${ }^{19}$ While every factor is not necessary to the production of every firm's output, we will write the production function with all factors as arguments; this simplifies the discussion to follow. An unused factor is termed 'redundant'. The output of firm $k$ in state $j$ is

$$
y_{k_{j}}=F_{k_{j}}\left(n_{1 k_{j}}, \ldots, n_{I k_{j}}, \sigma_{1 j}, \cdots, \sigma_{H j}\right) \text {. }
$$

The following restrictions are assumed to hold for the mobile factors,

$$
w_{i k_{j}}=\frac{\partial F_{k_{j}}}{\partial n_{i k_{j}}} \geq 0 \text { and if } \frac{\partial F_{k_{j}}}{\partial n_{i k_{j}}}>0 \text { then } \frac{\partial^{2} F_{k_{j}}}{\partial n_{i k_{j}}^{2}}<0 \text { and } \frac{\partial^{2} F_{k_{j}}}{\partial n_{i k_{j}} \partial n_{-i, k_{j}}}>0 \text {, }
$$

where $w_{i k_{j}}$ is the return for mobile factor $i$ used by firm $k$ in state $j$. This implies that every factor used by a firm enhances the productivity of every other factor that is used;

\footnotetext{
${ }^{19}$ The rationale for inclusion of state policies as arguments of the production functions is explained in Section IIa.
} 
thus, all factors are 'gross complements' ${ }^{20}$. Redundant factors will be those with zero marginal products. Policies are assumed to be either productivity neutral or augmenting,

$$
\frac{\partial F_{K j}}{\partial \sigma_{m j}} \geq 0, \frac{\partial^{2} F_{K j}}{\partial \sigma_{m j}^{2}} \leq 0, \frac{\partial^{2} w_{i K j}}{\partial n_{i k j} \partial \sigma_{m j}} \geq 0 \text {, and } \frac{\partial^{2} w_{i K j}}{\partial \sigma_{m j}^{2}} \leq 0 .
$$

The output of state $j$ is the sum of the value of firm specific outputs:

$$
y_{j}=y_{1 j}+\lambda_{2} y_{2 j}+\ldots+\lambda_{K} y_{K j} .
$$

Thus, $\lambda_{k}=1, \lambda_{2} \ldots, \lambda_{K}$ is the price of the output of firm $k$ relative to the numeraire output, $y_{1 j}$. State output is the weighted sum of the output of individual firms and can be written as a function of the total supply of each mobile factor of production (since the immobile factors are in fixed supply),

$$
y_{j}=y_{j}\left(n_{1 k_{j}}, \ldots, n_{I k_{j}}, \sigma_{1 j}, \cdots, \sigma_{M j}\right),
$$

where $y_{j}$ is quasi-concave and differentiable. The above is thought of as a 'regular technology', namely, each of the firms in a state has a strictly quasi concave production function, all factors (mobile and immobile) are complementary, and the output of all firms can be aggregated with fixed relative prices into a single numeraire output for a state, as given by (6.3).

Factor markets are perfectly competitive; each factor is paid the value of its marginal product. The return to a given mobile factor of production employed within state $j$ is the same across all firms, hence,

$$
w_{i k_{j}}=\frac{\partial F_{k_{j}}}{\partial n_{i k_{j}}}=\frac{\partial F_{-k_{j}}}{\partial n_{i,-k_{j}}}=w_{i,-k_{j}} \quad \forall i, k,-k
$$

where factor $i$ is not redundant. Since the production function is strictly quasi-concave in all non-redundant inputs, and all inputs are gross compliments, the return paid to a factor is monotonically decreasing in its own supply and monotonically increasing in the supply of all other non-redundant inputs. Therefore,

$$
\frac{\partial w_{i j}}{\partial n_{i j}}<0 \text { and } \frac{\partial w_{i j}}{\partial n_{-i j}}>0 .
$$

\footnotetext{
${ }^{20}$ Such a condition is also used in Keen and Marchand (1997).
} 
The vector of mobile inputs for state $j, n_{j}=\left[n_{1 j}, n_{2 j}, \cdots, n_{i j}, \cdots, n_{l j}\right]$, includes different types of mobile capital and different types of mobile labor. A mobile factor, be it capital or labor, is assumed to have preferences over its state specific return as well as a vector of policies, $\sigma_{j}$, chosen by the state. The index $m=1, \ldots . ., M$ denotes the policies used by state $j$ - these would include different types of tax/subsidies and local public goods (which may be impure or pure) such as education, health, law and order, environmental quality, or economic infrastructure (road and rail transport, ports, communications networks).

The preferences of mobile factor $i$ are represented by the payoff function $p_{i j}\left(\sigma_{j}, w_{i j}\left(n_{i j}\right)\right)$ which from now on is expressed as

$$
P_{i j}\left(\sigma_{j}, n_{i j}\right) \quad \forall i j .
$$

From Section II (d) the primitive conditions on preferences and technology ensure that the payoff function is strictly quasi-concave in $\sigma_{j}$, monotonically decreasing in $n_{i j}$ and continuous in both arguments. Within-bloc equilibrium for mobile factor $i$ requires

$$
P_{i j}\left(\sigma_{j}, n_{i j}\right)=P_{i-j}\left(\sigma_{-j}, n_{i-j}\right) \quad \forall i j
$$

As in the simple model $n_{i}$ is a non-decreasing function of the payoff received by the factor within the bloc. The within bloc payoff is equal across states so we can define $n_{i}$ (the supply of mobile factor $i$ to the regional bloc) as a non decreasing function of the payoff for the factor within any of the $j$ states

$$
n_{i}=n_{i}\left(P_{i j}\left(\sigma_{j}, n_{i j}\right)\right) \quad \forall i \text { and } n_{i} \leq N_{i} .
$$

The two equilibrium conditions (6.7) and (6.8) can be written as an implicit function for mobile factor $i$ (recall that $i=1, \ldots, I)$,

$$
h\left(\sigma_{j}, \sigma_{-j}, n_{j}\right)=P_{j}\left(\sigma_{j}, n_{j}\right)-P_{-j}\left(\sigma_{-j}, n\left(P_{j}\left(\sigma_{i}, n_{j}\right)\right)-n_{j}\right)=0 .
$$

There is a functional relationship between the supply of any particular mobile factor in state $j$ and the strategy vector adopted by the state, as shown in the following two propositions: 
Proposition 3: For $\sigma_{j} \in S_{j}$ there is a unique $n_{i j}$ that satisfies the factor market equilibrium conditions in (6.7) and (6.8). This implies a functional relationship between $\sigma_{j}$ and $n_{i j}$, conditional on the policy vectors adopted by the other states, $\sigma_{-j}$. In turn, this implies that we can define

$$
n_{i j}\left(\sigma_{j}, \sigma_{-j}\right) \forall i j .
$$

\section{Proof: See Annex B.}

Proposition 4: $n_{i j}\left(\sigma_{j}, \sigma_{-j}\right) \forall i j$ is a monotonically increasing, strictly quasi-concave and continuous function of $\sigma_{j}$ and $\sigma_{-j}$.

\section{Proof: See Annex B.}

With these results a formal statement of the sufficient conditions for the existence of equilibrium in the more general game is possible. Each state now aims to maximize

$$
V_{j}\left(n_{j}, \sigma_{j} \mid \sigma_{-j}\right)=B_{j}\left(n_{j}, \sigma_{j} \mid \sigma_{-j}\right)-C_{j}\left(n_{j} \mid \sigma_{-j}\right)
$$

Defining the state objective function as $\left.W_{j}\left(\sigma_{j}, \sigma_{-j}\right)\right) \equiv V_{j}\left(n_{j}, \sigma_{j} \mid \sigma_{-j}\right)$ it is possible to demonstrate the following:

Theorem 1: If $V_{j}\left(n_{j}, \sigma_{j} \mid \sigma_{-j}\right)$ is a continuous and strictly quasi- concave function of $n_{j}$ for all states $j$, then a pure strategy Nash equilibrium exists.

Proof: If $V_{j}\left(n_{j}, \sigma_{j} \mid \sigma_{-j}\right)$ is a continuous and strictly quasi-concave function of $n_{j}$ for all states $j$, then, because $n_{j}\left(\sigma_{j}, \sigma_{-j}\right)$ is continuous and strictly quasi-concave in $\sigma_{j}$ for all states (propositions 3 and 4$), W_{j}\left(\sigma_{j}, \sigma_{-j}\right)$ is continuous and strictly quasi-concave in $\sigma_{j}$ for all states. The policy game with inter-state fiscal competition is then defined on a non-empty, convex and compact Euclidian strategy space, $S$, and each state's objective is 
a continuous and strictly quasi-concave function of its own strategies. It follows that a pure strategy Nash equilibrium exists for the fiscal competition game ${ }^{21}$.//

Theorem 2: (Sufficient Condition for Existence): A sufficient condition for theorem 1 to be satisfied is that the benefit function for state $j$ should be concave in $n_{j}$ and the cost function should be convex in $n_{j}$.

Proof: Since $B_{j}(\cdot)$ and $C_{j}(\cdot)$ are continuous functions of $n_{j}, W_{j}\left(\sigma_{j}, \sigma_{-j}\right)$ is continuous and strictly quasi-concave in $\sigma_{j}$ if $B_{j}(\cdot)$ is a quasi-concave function of $n_{j}$ and if $C_{j}(\cdot)$ is a convex function of $n_{j} \forall i / /$.

Thus, as in the simple model with two instruments, one mobile factor and two states, in a regional bloc with multiple policy instruments, states and mobile factors, the sufficient condition for existence still depends on convexity of the cost function underlying the state's (separable) objective function, given that the benefit component of the objective is taken to be concave in mobile factor supplies.

\section{Conclusion.}

A fiscal competition game with two states, one mobile factor of production, and two policy instruments has been constructed in this paper. The model captures many of the features of the standard model found in the fiscal competition literature. It is shown that various concavity and continuity conditions arise from the mobile factor equilibrium conditions based on the primitives of the production technology and preferences. A separable state welfare function is then developed in which states choose a tax/subsidy and expenditure on a local public good which is productivity enhancing and benefits the mobile factor. Policies are chosen to maximize the difference between state benefit and the least cost (as represented by a cost function) of achieving the desired quantity of the mobile factor.

\footnotetext{
${ }^{21}$ Once again see Mas Colell, Whinston and Green, page 253.
} 
If concavity of the benefit part of the state welfare function is taken as given existence of equilibrium is shown to depend purely on the convexity of the cost function. The paper then shows that convexity, and hence existence, are not assured when local public goods are included in the strategy set of the states, and states use these public goods (as well as tax/subsidies) to compete with one another for mobile factors. Local public goods create economies of scale and problems for existence of equilibrium in fiscal competition games unless the public goods are super crowded. This is demonstrated in two examples, one with quasi linear preferences and the other with Leontieff preferences.

These results are also generalized to a model of a regional bloc with multiple states, mobile factors and policy instruments. The results on existence are then stated and proved for this generalized model using two theorems.

Use of the dual where states choose their policies to attract desired quantities of mobile factors at least cost, and allowing local public goods to enhance productivity of mobile factors are new ways of thinking about fiscal competition. The advantage of adopting this approach is to simplify the sufficient condition for existence and facilitate emphasis on the problem that public goods pose for existence, namely, non convexity of the cost function. With duality the sufficient condition is stated in terms of a straightforward convexity condition on the cost function underlying a state's objective.

Finally, the results suggest that non existence of Nash equilibrium in fiscal competition games is potentially a serious issue, especially in models where states have access to public goods which are insufficiently crowded. It makes no sense to examine the properties of models where there is no equilibrium. Fiscal competition models developed in future should explicitly consider existence prior to embarking on analyses of equilibrium outcomes, and drawing conclusions about the efficiency properties of fiscal competition. A fruitful way to proceed is to make use of the dual approach with a separable objective function which can be checked for the necessary convexity conditions described in this paper. 


\section{Annex A: Derivations Referred to in Footnotes 11, 12 and 13.}

\section{Footnote 11: Derivation of Cost Function (Quasi Linear Preferences)}

Letting effective public expenditure be $q_{j}^{*}=q_{j} / n_{j}^{2 \alpha}$ and the payoff to the mobile factor be $P_{j}=w_{j}+s_{j}+\sqrt{q_{j}} / n_{j}^{\alpha}$ then we have:

$$
\begin{array}{ll}
\left.\frac{d s_{j}}{d q_{j}}\right|_{\bar{P}_{j}}=-0.5 /\left(n_{j}^{\alpha} \sqrt{q_{j}}\right) & \text { (Slope of iso } n \text { curve) } \\
\left.\frac{d s_{j}}{d q_{j}}\right|_{\bar{c}_{j}}=-1 / n_{j} & \text { (slope of iso cost line) }
\end{array}
$$

Equating the two leads to a solution for the optimal 'effective' public good provision:

$$
q_{j}=\left(0.5 n_{j}^{1-\alpha}\right)^{2}
$$

And hence the optimal tax/subsidy:

$$
s_{j}=P_{-j}-0.5 / \sqrt{n_{j}}-0.5 n_{j}^{1-2 \alpha} .
$$

Using (3) and (4) in the iso cost equation $C_{j}=n_{j} s_{j}+q_{j}$ yields the least cost function:

$$
C_{j}\left(n_{j} \mid \sigma_{-j}\right)=n_{j} P_{-j}-0.5 \sqrt{n_{j}}-0.25 n_{j}^{2(1-\alpha)} .
$$

\section{Footnote 12: Derivatives of the Cost Function (Quasi Linear Preferences)}

From (5) above (or (5.3) in the main text) we obtain:

$$
\frac{d C_{j}}{d n_{j}}=P_{-j}+n_{j} \frac{d P_{-j}}{d n_{j}}-0.25 / \sqrt{n_{j}}-0.5(1-\alpha) n_{j}^{(1-2 \alpha)}
$$

and

$$
\frac{d^{2} C_{j}}{d n_{j}^{2}}=n_{j} \frac{d^{2} P_{-j}}{d n_{j}^{2}}+2 \frac{d P_{-j}}{d n_{j}}+0.125 n_{j}^{-3 / 2}-0.5(1-\alpha)(1-2 \alpha) n_{j}^{-2 \alpha}
$$

If $n$ is the total factor supply in the bloc

$$
P_{-j}=0.5\left(n-n_{j}\right)^{-1 / 2}+s_{-j}+\frac{\sqrt{q_{-j}}}{\left(n-n_{j}\right)^{\alpha}}
$$




$$
\begin{aligned}
& \left.\frac{d P_{-j}}{d n_{j}}\right|_{\bar{s}_{j}, \bar{q}_{j}}=0.25\left(n-n_{j}\right)^{-3 / 2}+\alpha \sqrt{q_{-j}}\left(n-n_{j}\right)^{-(1+\alpha)}>0 \\
& \frac{d^{2} P_{-j}}{d n_{j}^{2}}=(3 / 8)\left(n-n_{j}\right)^{-5 / 2}+\alpha(1-\alpha) \sqrt{q_{-j}}\left(n-n_{j}\right)^{-(2+\alpha)}>0
\end{aligned}
$$

\section{Footnote 13: Second Derivative of Benefit Function (Quasi Linear Preferences)}

Let

$$
B_{j}=0.5 \sqrt{n_{j}}
$$

The first derivative is

$$
\frac{d B_{j}}{d n_{j}}=0.25 / \sqrt{n_{j}}>0
$$

and the second derivative is

$$
\frac{d^{2} B_{j}}{d n_{j}^{2}}=-0.125 n_{j}^{-3 / 2}<0 .
$$

For the symmetric case this is:

$$
\frac{d^{2} B_{j}}{d n_{j}^{2}}=-0.125(0.5 n)^{-3 / 2}<0 \text {. }
$$




\section{Annex B: Proofs for Propositions 3 and 4}

Proof of Proposition 3: For fixed $\sigma \in S$ the factor market equilibrium conditions represent a mapping from the set $N_{i}$ into itself. The continuity of the mapping and the compactness and convexity of $\mathrm{N}$ ensure that there is at least one fixed point, $n^{*}$, of that mapping.

Suppose there is more than one solution, say two $n^{*}$ and $n^{\prime}$, then, without loss of generality, there is at least one $n_{i j}^{*}>n_{i j}^{\prime}$. Since the factor market is regular, the payoffs to all other factors, but factor $i(-i)$, are higher in state $j$ with * than with '. Consequently to maintain factor market equilibrium the payoffs to all other factors must be higher in all states. The implication of higher payoffs for $-i$ factors needs to be examined in the case of a fixed supply of factors in the federation and the case in which factors can move in and out of the federation.

For fixed federation factor supply implication of $-i$ higher payoffs, since factor markets are regular, is that the supply of factor $i$ in all states (the use of factor $i$ in all industries in all states) must be higher in * than in ' . This is impossible since it would violate fixed supply: a contradiction.

For variable federation factor supply, by reasoning similar to the fixed supply case, more of each factor must be attracted to the federation with * than with '. This means that all factor payoffs must be larger with * than with '. Since the state strategies are fixed, the wage to every factor must be higher with * than with '. Let the marginal product of a typical firm in a state be $F_{j}\left(n_{j}\right)$ and let its Hessian matrix of second derivative be $D_{j}$. Let $d n_{j}$ and $d w_{j}$ be column vectors of changes in factor use and changes in factor wages respectively. The change in factor wage is related to the change in factor use in the following way

$$
D_{j} d n_{j}=d w_{j .} .
$$

The quadratic form is then

$$
d n_{j}{ }^{\prime} D_{j} d n_{j}=d n_{j}{ }^{\prime} d w_{j} .
$$

Because the production function is strictly quasi concave the left hand side of the equation is negative and for there to be two solutions to the market equilibrium conditions the right hand side must be negative: a contradiction. /// 
Proof of Proposition 4: Define $L\left(\sigma_{-j}, n_{j}\right)=\left\{\sigma_{j} \mid h\left(\sigma_{j}, \sigma_{-j}, n_{j}\right)=0\right\}$ as the level set of state $j$ strategy vectors that satisfy (6.9) for given $\sigma_{-j}$ and $n_{j}$. [Another way to define the level set is as follows - it is the set of values of $\sigma_{j}$ that satisfies the equation $n_{j}^{0}=n_{j}\left(\sigma_{j}, \sigma_{-j}^{0}\right)$ where the 0 superscript indicates fixed values of $n_{j}$ and $\sigma_{j}$. From this we then have that $L\left(\sigma_{-j}^{0}, n_{j}^{0}\right)=\left\{\sigma_{j} \mid n_{j}\left(\sigma_{j}, \sigma_{-j}^{0}\right)=n_{j}^{0}\right\}$. Notice that $P_{j}\left(\sigma_{j}, n_{j}\right)$ is the same for all $\sigma_{j} \in L\left(\sigma_{-j}, n_{j}\right)$ for a given values of $\left.n_{j}\right]$.

\section{(a) Concavity}

Define $\sigma^{\lambda}=\lambda \sigma_{j}^{0}+(1-\lambda) \sigma_{j}^{1}$ for $\sigma_{j}^{0}, \sigma_{j}^{1} \in L\left(\sigma_{-j}, n_{j}\right)$ and $0 \leq \lambda \leq 1$.

Because $P_{j}$ is concave in $\sigma_{j}$, thus $P_{j}\left(\sigma_{j}^{\lambda}, n_{j}\right)>P_{j}\left(\sigma_{j}^{0}, n_{j}\right)$ and $h(\cdot)$ is continuous and monotonically increasing in $P_{j}$.

$h\left(\sigma_{j}^{\lambda}, \sigma_{-j}, n_{j}\right) \geq 0$

There exists a unique $n_{i}^{\lambda}$ such that $h\left(\sigma_{j}^{\lambda}, \sigma_{-j}, n_{j}^{\lambda}\right)=0$.

Because $h(\cdot)$ is monotonically decreasing in $n_{j}$ $n_{j}^{\lambda} \geq n_{j}$.

Therefore $n_{j}\left(\sigma_{j}^{\lambda}, \sigma_{-j}\right) \geq n_{j}\left(\sigma_{j}, \sigma_{-j}\right)$ and $n_{j}$ is strictly quasi concave in $\sigma_{j}$

\section{(b) Continuity}

We now show that the function $n_{j}(\cdot)$ is continuous in $\sigma_{j}$ for given $\sigma_{-j}=\bar{\sigma}_{-j}$. The same argument applies to showing that $n_{j}(\cdot)$ is continuous in $\sigma_{-j}$. Suppose $n_{j}(\cdot)$ is not a continuous function of $\sigma_{j}$. Then there are at least two distinct sequences, $\left(\sigma_{j}^{k}\right)_{k} \in S_{j}$ and $\left(\sigma_{\mathrm{j}}^{\mathrm{m}}\right)_{m} \in S_{j}$ 
that converge to the same value

$$
\lim _{k \rightarrow \infty}\left(\sigma_{j}^{k}\right)_{k}=\lim _{m \rightarrow \infty}\left(\sigma_{j}^{m}\right)_{m}=\bar{\sigma}_{j} \in S_{j}
$$

such that

$\lim _{k \rightarrow \infty} n_{i j}\left(\left(\sigma_{j}^{k}\right)_{k}, \bar{\sigma}_{-j}\right)=n_{j}^{\prime}$

and $n_{j}^{\prime}<n_{j}^{\prime \prime}$

$\lim _{m \rightarrow \infty} n_{j}\left(\left(\sigma_{j}^{m}\right)_{m}, \bar{\sigma}_{-j}\right)=n_{j}^{\prime \prime}$.

From the definition of $h(\cdot)$

$h\left(\sigma_{j}^{k}, \bar{\sigma}_{-j}, n_{j}\left(\sigma_{j}^{k}, \bar{\sigma}_{-j}\right)\right)=h\left(\sigma_{j}^{m}, \bar{\sigma}_{-j}, n_{j}\left(\sigma_{j}^{m}, \bar{\sigma}_{-j}\right)\right)=0 \forall k, m$.

By the continuity of $h(\cdot)$

$\lim _{k \rightarrow \infty} h\left(\sigma_{j}^{k}, \bar{\sigma}_{-j}, n_{j}\left(\sigma_{j}^{k}, \bar{\sigma}_{-j}\right)\right)=h\left(\bar{\sigma}_{j}, \bar{\sigma}_{-j}, n_{j}^{\prime}\right)=0$

and

$\lim _{m \rightarrow \infty} h\left(\sigma_{j}^{m}, \bar{\sigma}_{-j}, n_{j}\left(\sigma_{j}^{m}, \bar{\sigma}_{-j}\right)\right)=h\left(\bar{\sigma}_{j}, \bar{\sigma}_{-j}, n_{j}^{\prime \prime}\right)=0$.

But

$h\left(\sigma_{j}^{\prime}, \bar{\sigma}_{-j}, n_{j}^{\prime}\right)>h\left(\sigma_{j}^{\prime}, \bar{\sigma}_{-j}, n_{j}^{\prime}\right)$.

The contradiction proves the assertion that $n_{j}(\cdot)$ is continuous in $\sigma_{j}$ for fixed $\sigma_{-j}=\bar{\sigma}_{-j} . / /$

\section{(c) Increasing}

Because $P_{j}(\cdot)$ is monotonically increasing in $\sigma_{j}$ and $n_{j}(\cdot)$ is

monotonically increasing in $P_{j}(\cdot)$, it follows that $n_{j}(\cdot)$ is monotonically increasing in $\sigma_{j}$ 


\section{References}

Bayindir-Upmann, T, and A. Ziad (2005), Existence of Equilibria in a Basic TaxCompetition Model, Regional Science and Urban Economics, 35, 1-22.

Bewley, T (1981), A Critique of Tiebout's Theory of Local Public Expenditures, Econometrica, 49:3, 713-740.

Braid, R.M (1996). Symmetric Tax Competition with Multiple Jurisdictions in Each Metropolitan Area, American Economic Review, 86, 1279-1290.

Brennan, G., and J. Buchanan (1980), The Power to Tax: Analytical Foundations of a Fiscal Constitution, Cambridge University Press, New York.

Bucovetsky, S (1991), Asymmetric Tax Competition, Journal of Urban Economics, 30, 167-81.

Bucovetsky, S, and J.D. Wilson (1991), Tax Competition with Two Tax Instruments, Regional Science and Urban Economics, 21, 333-350.

Cremer, H., Fouregeaud, M., Monteiro, L., Marchand. M., and P. Pestieau (1996), Mobility and Redistribution: A Survey of the Literature, Public Finance, 51, 325-52.

Edwards, J, and M. Keen (1996), Tax Competition and Leviathan, European Economic Review, 40, 113-134.

Jehle, G.A., and P.J. Reny (2000), Advanced Microeconomic Theory, Second Edition, Adison Wesley.

Keen, M and C. Kotsogiannis (2003), Leviathan and Capital Tax Competition in Federations, Journal of Public Economic Theory, 5:2, 177-199.

Keen, M, and M. Marchand (1997), Fiscal Competition and the Pattern of Public Spending, Journal of Public Economics, 66, 33-53.

Konrad, K.A, and G. Schjelderup (1999), Fortress Building in Global Tax Competition, Journal of Urban Economics, 46, 156-167.

Krelove, R (1992), Efficient Tax Exporting, The Canadian Journal of Economics, 25:1, 145-155.

Laussel, D., and M Le Breton (1998), Existence of Nash Equilibria in Fiscal Competition Models, Regional Science and Urban Economics, 28: 283-96.

Lee, K (1997), Tax Competition with Imperfectly Mobile Capital, Journal of Urban Economics, 42, 222-242. 
Mas-Colell, A., M.D. Whinston and J.R. Green (1995), Microeconomic Theory, Oxford University Press.

Mendoza, E.G. and L.L Tesar (2005), Why Hasn't Tax Competition Triggered a Race to the Bottom? Some Quantitative Lessons from the EU, Journal of Monetary Economics, $52,163-204$.

Oates, W.E and R.M Schwab (1988), Economic Competition Among Jurisdictions:

Efficiency Enhancing or Distortion Inducing? Journal of Public Economics, 35, 333-354.

Parry, I.W (2003), How Large are the Welfare Costs of Tax Competition? Journal of Urban Economics, 54, 39-60.

Petchey, J.D and P. Shapiro (2002), State Tax and Policy Competition for Mobile Capital, The Economic Record, 78:241, 175-185.

Sorensen, P.B (2003), International Tax Coordination: Regionalism vs Globalism, Journal of Public Economics, 88, 1187-1214.

Wilson J.D (1991), Tax Competition with Inter Regional Differences in Factor Endowments, Regional Science and Urban Economics, 21, 423-451.

Wilson, J.D and D.E. Wildasin (2004), Capital tax competition: Bane or Boon, Journal of Public Economics, 88, 1065-91.

Whitman, Donald (1989). Why Democracies Produce Efficient Results The Journal of Political Economy 97:6, 1395-1424.

Wildasin, D.E. (1988). Nash Equilibrium in Models of Fiscal Competition, Journal of Public Economics, 35, 229-240.

Wildasin, D.E (1989), Inter jurisdictional Capital Mobility: Fiscal Externality and a Corrective Subsidy, Journal of Urban Economics, 25, 193-212.

Wildasin, D.E. (1991). Some Rudimentary 'Duopolity' Theory, Regional Science and Urban Economics, 21, 393-421.

Wildasin, D.E., and J.D. Wilson (1991), Theoretical Issues in Local Public Economics, Regional Science and Urban Economics, 21, 317-331.

Zodrow, G.R, and P. Mieszkowski (1986), Pigou, Tiebout, Property Taxation, and the Under Provision of Local Public Goods, Journal of Urban Economics, 19, 356-370. 